\title{
THE INTERRELATIONS OF SERUM LIPIDS IN PATIENTS WITH THYROID DISEASE ${ }^{1}$
}

\author{
By JOHN P. PETERS AND EVELYN B. MAN \\ (From the Departments of Internal Medicine and Psychiatry of the Yale University School \\ of Medicine, New Haven)
}

(Received for publication January 26, 1943)

Numerous observers have reported that in both clinical and experimental hyperthyroidism, total fatty acids, lipid phosphorus, and cholesterol of the blood serum tend to be low, while in myxedema they are usually elevated. There is, however, no agreement about the consistency or significance of these changes.

Gildea, Man, and Peters (1) found that the serum cholesterol in myxedema was usually at or above the upper normal limits. Lipid phosphorus was elevated proportionally. With thyroid therapy, both returned to normal together. The concentration of cholesterol in the serum in the myxedematous state could not be correlated with the basal metabolism nor with other manifestations of the disease. The reduction of cholesterol with thyroid therapy was roughly proportional to the concentration of cholesterol in the serum during the myxedematous condition. The higher the initial cholesterol, the more it appeared to fall under the influence of a given dose of thyroid. From Figure 2 of the paper by Gildea, Man, and Peters, it can be seen that the final cholesterol attained with adequate therapy was, in most instances, related to the initial myxedematous concentration. An extremely high initial cholesterol came to rest in the upper part of the normal range; a cholesterol that was initially only slightly elevated fell to the lower part of the normal range. This suggests that when hypercholesterolemia develops through loss of thyroid function, the inherent characteristics which determine the normal concentration of cholesterol in the individual are not lost. This hypothesis must be advanced with some reserve, since it is impossible to state with certainty, in most instances, that therapy has produced the perfect euthyroid state. It is, however, supported by data of Gilligan, Volk, Davis, and Blumgart

${ }^{1}$ This investigation was aided by grants from the Knight Fund and the Fluid Research Fund of the Yale University School of Medicine.
(2), from patients who were subjected to total thyroidectomy for the relief of heart failure.

In hyperthyroidism, cholesterol and lipid phosphorus are reduced (3). Again, however, the actual concentration of cholesterol in the serum is not closely correlated with the severity of the hy-

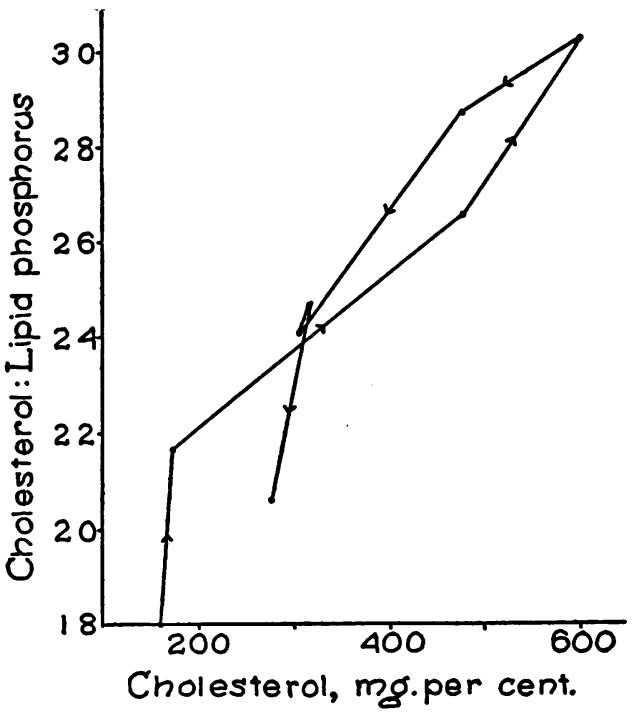

Fig. 1. The Relation of Cholesterol to the Ratio, Cholesterol: Lipid Phosphorus, in a Patient Who, After an Operation for Thyrotoxicosis, Developed Myxedema, Which was Treated with Dried THYROID

The lines with arrows describe the sequence of events in the course of treatment.

perthyroidism, but rather with the individual's normal cholesterol concentration. It may, therefore, lie within normal limits, even at the height of thyrotoxicosis. Under the influence of iodine, or after thyroidectomy, cholesterol and lipid phosphorus rose to normal concentrations.

The ratio of cholesterol to lipid phosphorus, in both hypothyroids and hyperthyroids, at any given concentration of cholesterol does not differ from that of normal individuals. This is clear from 
Figure 3 of the paper of Gildea, Man, and Peters (1) and Figure 4 of Man, Gildea, and Peters (3). When a hyperthyroid improves after thyroidectomy, cholesterol and lipid phosphorus rise together, following approximately the mean line describing the average relation of the two functions in normals. When a patient with myxedema is treated with thyroid preparations, cholesterol and lipid phosphorus fall together along a curve that is continuous with the same mean line. These relations are presented in Table III of the pre- ceding article (4). It may be seen from this table that the ratio in normal persons, psychiatric patients, obese subjects, malnourished individuals, and patients with thyroid disease has the same distribution within the range of normal variation. Below this, malnutrition and hyperthyroidism fall together; above it, myxedema, in such a manner as to form a smooth, continuous curve. So far as the ratio of cholesterol to lipid phosphorus is concerned, therefore, hyperthyroids and hypothyroids are indistinguishable from normals at any given

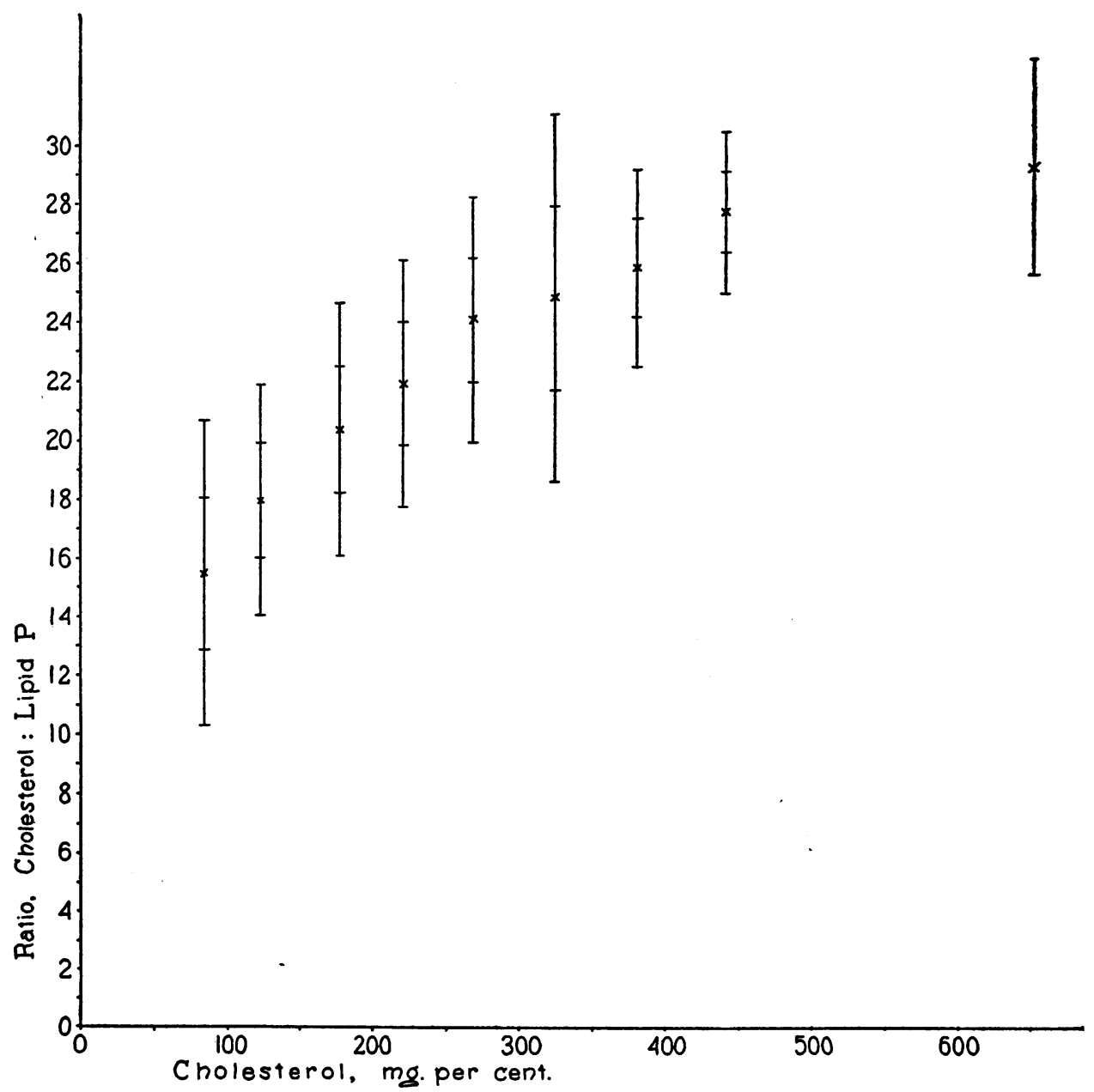

Fig. 2. The Relation of Cholesterol to the Ratio, Cholesterol: Lipid Phosphorus, in the Serum of Normal Persons, Psychiatric Patients, and Patients with Diseases of THE THYROID

Observations were divided into classes, depending upon the concentration of cholesterol. From 50 to 400 , they have been divided at intervals of 50 , above this into two classes, one of 400 to 500 , the other of 500 or more.

The crosses represent mean concentrations for each class. The vertical lines and cross lines indicate once and twice the standard deviation, except in the highest class where only the standard deviation is given. 


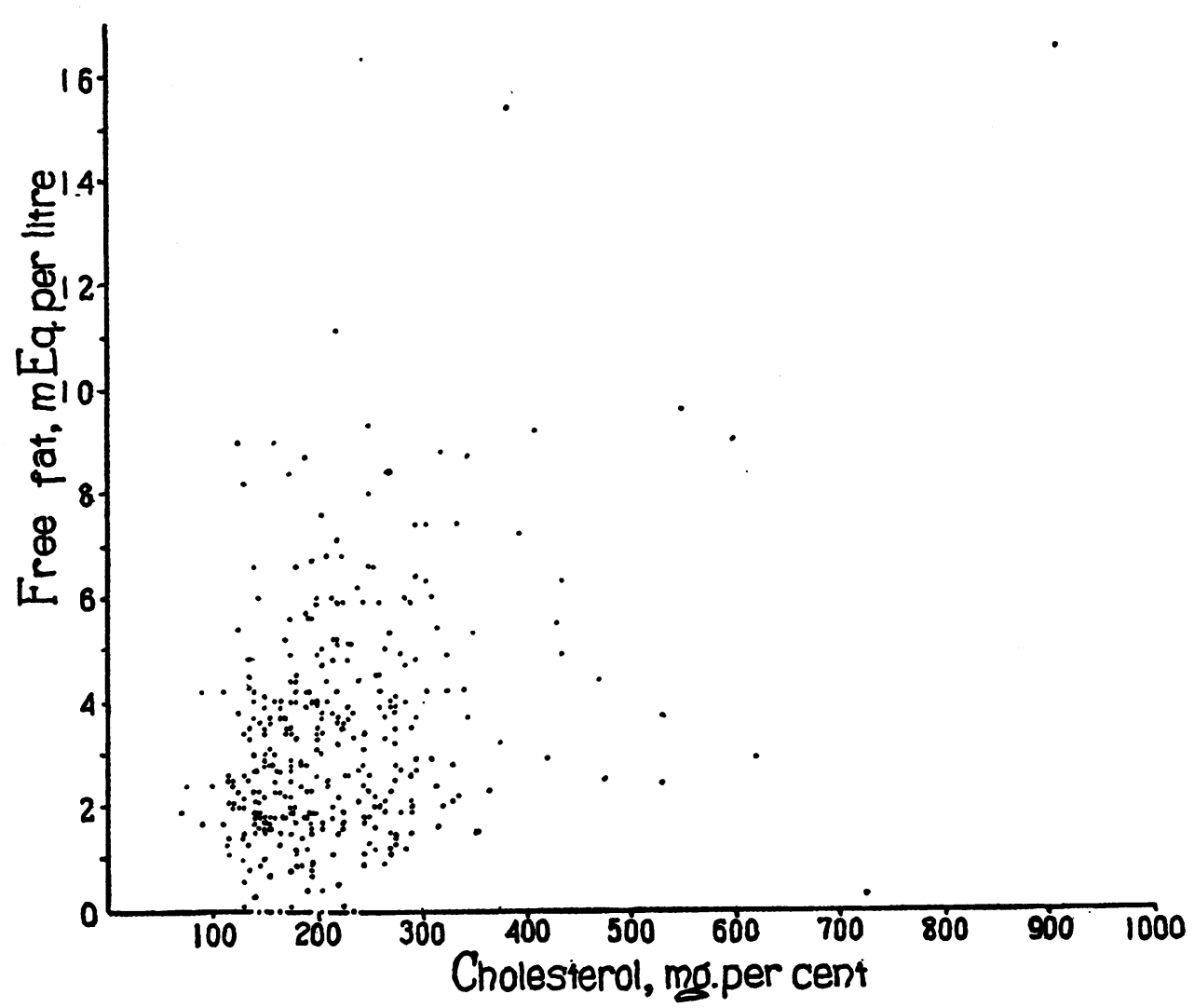

Fig. 3. The Relation of Free Fat to Cholesterol in Patents with Thyroid Disease

concentration of cholesterol. The continuity of the course of this ratio is well illustrated in Figure 1 , describing the changes of cholesterol and lipid phosphorus in the serum of a woman who was first seen with hyperthyroidism, developed myxedema after thyroidectomy, and was subsequently treated with thyroid substance.

Thompson and Long (5) found that in dogs, as in humans, cholesterol rose after thyroidectomy. After hypophysectomy, however, it fell again. This led them to conclude that the hypercholesterolemia of myxedema was not referable to the elimination of thyroid activity per se, but to overactivity of the anterior lobe (presumably thyrotropic hormone), provoked by absence of the thyroid. Entenman, Chaikoff, and Reichert $(6,7)$ repeated these experiments with pair-fed animals. Under these circumstances, they found that the fall of serum cholesterol, after removal of the pituitary, arose only from the failure of hypophysectomized animals to eat. The cholesterol of simply thyroidectomized animals rose no more than that of thyroidectomized hypophysectomized animals if the diets of the former were limited to the quantities of food voluntarily taken by the latter. On the other hand, the cholesterol of the thyro-hypophysectomized animals rose quite as much as that of the simply thyroidectomized if the former were given by gavage as much food as the latter took voluntarily. Thyroidectomy, therefore, appeared merely to enhance the susceptibility of serum lipids to the influence of diet.

Figure 2, and Table I, therefore, which define the relation of cholesterol to the ratio, cholesterol :lipid $\mathrm{P}$, may be regarded as describing the effects of diet on cholesterol and lipid phosphorus, if the word diet is used in a limited sense. It has already been pointed out that the states of obesity and thinness are not associated with any characteristic concentrations or proportions of cholesterol and lipid P. Myxedema is not necessarily accompanied by obesity. Entenman and his associates (7) call attention to the fact that their thyroidectomized dogs developed hypercholestero- 
TABLE I

Relation of cholesterol to ratio, Cholesterol: Lipid $P$, in normal and psychiatric subjects and patients with diseases of the thyroid gland

\begin{tabular}{r|r|r|r|r}
\hline \hline \multirow{2}{*}{$\begin{array}{c}\text { Number } \\
\text { of } \\
\text { observa- } \\
\text { tions }\end{array}$} & \multicolumn{2}{|c|}{ Cholesterol } & \multicolumn{2}{c}{ Cholesterol : Lipid P } \\
\cline { 2 - 3 } \cline { 5 - 5 } & Range & Mean & Mean & S.D. \\
\cline { 2 - 5 } 9 & \multicolumn{2}{|c|}{ mgm. per 100 cc. } & & \\
9 & 64 to 97 & 83.4 & 15.45 & \pm 2.59 \\
139 & 100 to 149 & 132.7 & 17.97 & \pm 1.96 \\
316 & 150 to 199 & 176.8 & 20.34 & \pm 2.14 \\
257 & 200 to 249 & 221.2 & 21.92 & \pm 2.08 \\
100 & 250 to 299 & 269.4 & 24.07 & \pm 2.08 \\
19 & 300 to 349 & 324.8 & 24.82 & \pm 3.12 \\
4 & 350 to 399 & 380.4 & 25.80 & \pm 1.67 \\
8 & 410 to 475 & 441.4 & 27.71 & \pm 1.38 \\
7 & 500 to 911 & 651.6 & 29.30 & \pm 3.68 \\
\hline
\end{tabular}

lemia without obesity. Thyroidectomy made the cholesterol more responsive to dietary influences. Similarly, although hyperthyroidism usually leads to loss of weight, patients with thyrotoxicosis are not necessarily undernourished. There is little correlation between serum cholesterol and either weight loss or serum albumin in hyperthyroidism. Although thyroid activity may exert a great influence upon the concentrations of serum lipids without disturbing their normal interrelationships, it cannot be responsible for the major differences between individuals, since these are maintained after removal of the thyroid.

The ratio of free to total cholesterol was determined 12 times in 9 patients with thyroid disease. Only once did it depart from the normal limits of 0.24 to 0.32 . The serum cholesterol of the patients with normal ratios varied from 129 to 911 mgm. per cent. In the one exception, with a total cholesterol of $550 \mathrm{mgm}$. per cent and a ratio of 0.21 , the patient was suffering from heart failure and other complications. On the whole, neither hyperthyroidism nor myxedema appears to have any specific effect upon the partition of cholesterol in humans. In dogs, Entenman et al. $(6,7)$ found that free cholesterol and lipid phosphorus were both less affected than cholesterol esters. This probably does not denote a difference between the reactions of the two species, but merely arises from the fact that Entenman analyzed whole blood. Since cells contain no cholesterol esters (8), while 70 per cent of the cholesterol of serum consists of esters, if both fractions rose proportionally in serum while the contents of the cells remained unchanged, the increment in whole blood would appear to consist almost solely of esters. Likewise, if cellular lipid phosphorus remained constant, the rise of lipid phosphorus would be less evident in analyses of whole blood.

It has been reported that the free fat of the blood, like the cholesterol and lipid phosphorus, is low in hyperthyroidism $(9,10)$ and high in myxedema $(11,12)$. Man, Gildea, and Peters $(1,3)$ found a correlation between cholesterol and total fatty acids, but this was less exact than the correlation between cholesterol and lipid phosphorus. Since most of the fatty acid of serum belongs to cholesterol esters and phospholipids, there would have to be some correlation between cholesterol and fatty acids. When neutral fat itself is compared with cholesterol, however, no consistent
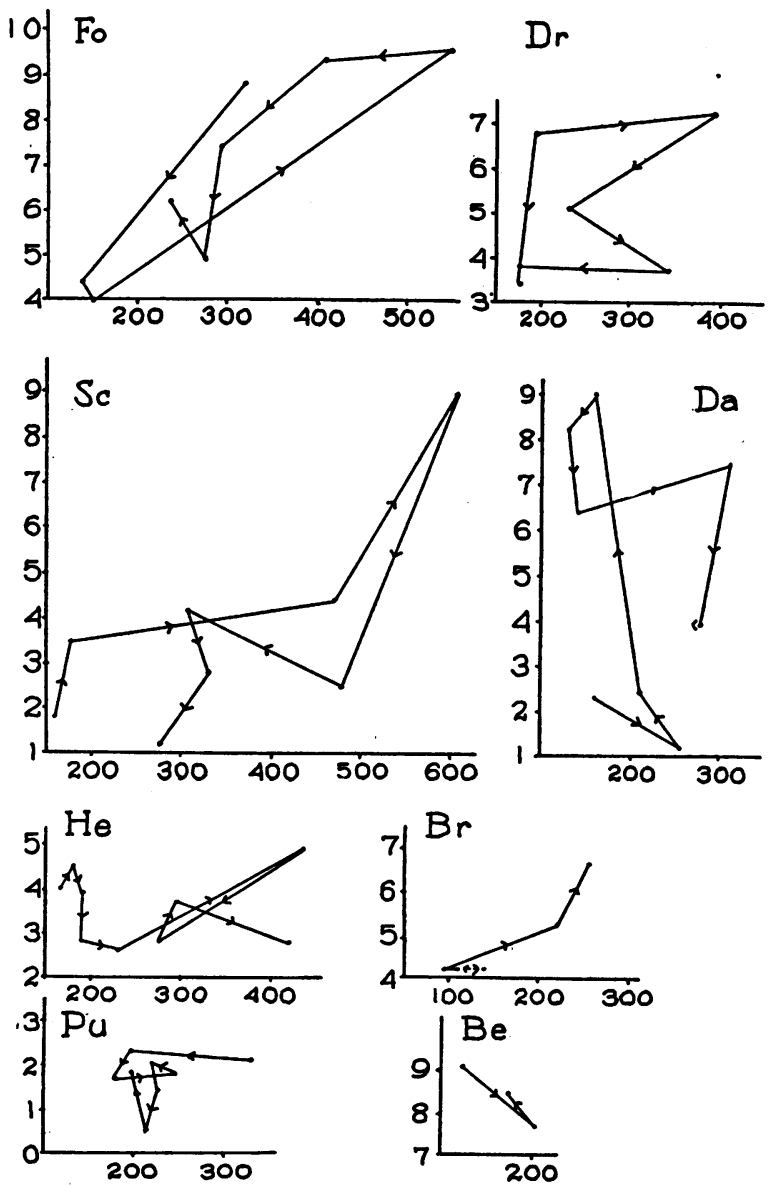

Fig. 4. The Course and Relations of Cholesterol and Free fat in Response to Therapy in a Representative Series of Patients with Thyroid Disease

In all cases, ordinates represent free fat in terms of m.eq. of fatty acid per liter, abscissae represent cholesterol in mgm. per cent. 
relationship can be recognized. This is evident from Figure 3. There are, perhaps, more high fats in conjunction with high cholesterols; but high fat values appear sporadically with all concentrations of cholesterol. When individuals with multiple observations are examined, the same absence of correlation is noted. Although extremely high cholesterols sometimes coincide with high neutral fats, startling exceptions are encountered. Some subjects tend to maintain fat at a low level, despite wide variations of cholesterol, while in others fat is consistently high. Cases illustrating these differences are shown in Figure 4. The variations of cholesterol represent responses to iodine, thyroidectomy, or thyroid substance. The course is indicated in each case by the connecting lines with arrows. In $\mathrm{Fo}$ and $\mathrm{Br}$, fat and cholesterol parallel one another roughly; in Sc they reach their peak together. In $\mathrm{Be}$, on the other hand, the two fractions vary inversely and fat is continuously high, while cholesterol is low. In $\mathrm{He}$ and $\mathrm{Pu}$, fat remains low while cholesterol swings widely. In $\mathrm{Da}$, the two highest figures for fat coincide with two of the lowest cholesterol values, obtained while the patient was in a severely hyperthyroid state. In this case and in $\mathrm{Dr}$, there is no semblance of order.

Perhaps the best evidence that thyroidectomy has no specific effect upon free fat is found in two patients with hypertension who were subjected to total thyroidectomy. In one, while cholesterol rose from 286 to $612 \mathrm{mgm}$. per cent, free fat went from 2.8 to 5.8 m.eq. per liter. It had, however, been as high as 4.8 m.eq. per liter on two occasions before thyroidectomy and was as high as $\mathbf{5 . 8}$ only once after operation, falling again to 4.6 while cholesterol was still $590 \mathrm{mgm}$. per cent. In the other patient, before operation, when cholesterol varied from 208 to $238 \mathrm{mgm}$. per cent, neutral fat varied from 8.5 to 5.4 m.eq. per liter; after thyroidectomy, when cholesterol varied from 288 to $407 \mathrm{mgm}$. per cent, neutral fat varied from 8.5 to 5.1 m.eq. per liter.

\section{SUMMARY AND CONCLUSIONS}

The lipids of the serum of a large number of patients with thyroid disease have been analyzed.

Although cholesterol rises when the thyroid gland is removed and falls when active thyroid preparations are given, normal concentrations of cholesterol may be found in the serum of patients with hyperthyroidism or with thyroid deficiency, because the level to which cholesterol falls or rises with these disorders is roughly related to the normal cholesterol concentration of the affected subject.

The ratios of free to total cholesterol and of cholesterol to lipid phosphorus are not affected by disorders of thyroid function. The latter ratio, within the normal range of cholesterol, is the same for patients with normal, excessive, or deficient thyroid activity, varying with the concentration of cholesterol. As cholesterol falls below this range in hyperthyroidism, the ratio diminishes as it does in malnutrition. As cholesterol rises above this range, the ratio rises to describe a continuous curve.

The relation of cholesterol to lipid phosphorus in normals, psychiatric subjects, and patients with thyroid disease has been defined.

There is no relation between the height of cholesterol and the level of neutral fat in the serum.

\section{BIBLIOGRAPHY}

1. Gildea, E. F., Man, E. B., and Peters, J. P., Serum lipoids and proteins in hypothyroidism. J. Clin. Invest., 1939, 18, 739.

2. Gilligan, D. R., Volk, M. C., Davis, D., and Blumgart, H. L., Therapeutic effect of total ablation of normal thyroid on congestive heart failure and angina pectoris. VIII. Relationship between serum cholesterol values, basal metabolic rate and clinical aspects of hypothyroidism. Arch. Int. Med., 1934, 54, 746.

3. Man, E. B., Gildea, E. F., and Peters, J. P., Serum lipoids and proteins in hyperthyroidism. J. Clin. Invest., 1940, 19, 43.

4. Peters, J. P., and Man, E. B., The interrelations of serum lipids in normal persons. J. Clin. Invest., 1943, 22,

5. Thompson, K. W., and Long, C. N. H., The effect of hypophysectomy upon hypercholesterolemia of dogs. Endocrinol., 1941, 28, 715.

6. Entenman, C., Chaikoff, I. L., and Reichert, F. L., Rôle of nutrition in response of blood lipids to thyroidectomy. Endocrinol., 1942, 30, 794.

7. Entenman, C., Chaikoff, I. L., and Reichert, F. L., Blood lipids of the hypophysectomized-thyroidectomized dog. Ibid., 802.

8. Brun, G. C., Cholesterol Content of the Red Blood Cells in Man. H. K. Lewis, London, 1939.

9. Bing, H. I., and Heckscher, H., Untersuchungen über Lipämie. II. Uber die Fettmenge des Blutes bei 
normalen Menschen. Biochem. Ztschr., 1924, 149, 83.

10. Bing, H. J., and Heckscher, H., Der Fett-Cholesteringehalt des Blutes bei Patienten mit Morbus Basedowii. Biochem. Ztschr., 1925, 158, 403.
11. Heckscher, H., Untersuchungen über den Fett-Cholesterin-Gehalt des Blutes bei thyreodectomierten Pferden. Ibid., 417.

12. Heckscher, H., Uber die Fett-Cholesterin-Menge des Blutes bei Kretinen. Ibid., 422. 